\title{
Hematological Profile In Cases Of Chronic Renal Diseases.
}

\author{
Pranami Dewan ${ }^{1}$ Nanda Patil ${ }^{2}$, Mamta Bharti ${ }^{3}$ \\ ${ }^{1}$ Undergraduate II MBBS student \\ ${ }^{2}$ Professor, Department of Pathology \\ ${ }^{3}$ Tutor, Department of Pathology \\ Krishna Institute of Medical Sciences, Karad, Maharashtra
}

\section{Introduction}

The incidence and prevalence of chronic renal disease is increasing worldwide. The incidence of new end stage renal disease in India is 100 per million population per year ( Gedela ${ }^{1}$ ). In India Diabetes mellitus, hypertension, glomerulonephritis and chronic interstitial nephritis are the leading causes of chronic kidney diseases. The hematological profile has a major impact on the quality of life of patients with chronic renal disease. Anemia is seen consistently in these patients contributing morbidity and mortality. Leucocyte and platelet disorder have also been described in cases of renal failure. ${ }^{5}$ Managing these co-morbid conditions can improve the quality of life in these cases. The present study was done to assess hematological parameters in case of chronic renal disease in a tertiary care hospital.

\section{Objective}

To study the hematological parameters in cases of chronic renal disease.

\section{Material and Method}

A descriptive study was carried out over a period of two months (August-September) in 2016to evaluate the hematological changes in patients of chronic renal disease. The study was carried out after ethical clearance from the institute. The cases of chronic renal disease referred to our institute irrespective of age and sex were included in the study. The cases subjected to hemodialysis and renal transplant were excluded. Detail clinical history of patients was collected and after informed consent blood samples were taken for hematological and biochemical tests including hemoglobin estimation total and differential leucocyte count, platelet count, hematological indices and blood urea and creatinine levels.

\section{Results}

The study included a total of 32 cases with chronic renal disease, the age group ranged from 29 to 75 years. Majority of cases (10 cases- $31.25 \%$ ) were in the age group of 70 to 80 years the mean age being 58 years. Amongst total 32 cases, 27 cases $(84.37 \%$ ) were male patients while $15.62 \%$ that is, 5 cases were female. Male is to female ratio being 5.4:1. All these cases revealed increased level of blood urea level that ranged from 61 to $490 \mathrm{mg} / \mathrm{dl}$. The creatinine values were also raised in all these cases which ranged from $3.4 \mathrm{mg} / \mathrm{dl}$ to $11.3 \mathrm{mg} / \mathrm{dl}$.

The etiology of chronic renal failure was type-II diabetes mellitus 8 cases (25\%) obstructive uropathy 5 cases (15.62\%), hypertension 3 cases $(9.37 \%)$ and renal tuberculosis and use of NSAID in 1 case each $(3.125 \%)$ and in remaining 14 cases etiology was not known.

Table 1: The diseases related to chronic renal failure

\begin{tabular}{|l|l|l|}
\hline Diseases & Frequency & Percentage \\
\hline Type II Diabetes & 8 & $25 \%$ \\
\hline Obstructive uropathy & 5 & $15.62 \%$ \\
\hline Hypertension & 3 & $9.37 \%$ \\
\hline Renal Tuberculosis & 1 & $3.125 \%$ \\
\hline NSAID & 1 & $3.125 \%$ \\
\hline No definite etiology & 14 & $43.7 \%$ \\
\hline Total & 32 & $100 \%$ \\
\hline
\end{tabular}

Hematological profile in cases of chronic renal disease. Anemia was seen in all of CRF patients. The hemoglobin level ranged from $4.9 \mathrm{gm} / \mathrm{dl}$ to $11.4 \mathrm{gm} / \mathrm{dl}$, the mean hemoglobin value was $8.7 \mathrm{gm} / \mathrm{dl}$. Majority of cases (16 cases- $50 \%$ presented with moderate anemia. Peripheral blood smear and hematological indices in these cases revealed normocytic normochromic blood picture in 31cases (96.87\%) and macrocytic anemia in 1 case (3.12\%). Total leukocyte count in these cases ranged from 4800 to $21,600 / \mathrm{cmm}$. 
Normal total and differential WBC count was seen in majority of cases (28 cases i.e. 87.5). Four cases $(12.5 \%)$ revealed increased WBC count and neutrophilia. Amongst these two cases each were having septicemia and pneumonia. Platelet count was normal in 24cases $(75 \%)$ of chronic renal failure. While 6cases $(18.75 \%)$ revealed thrombocytopenia. Platelet count was increased in 2 cases $(6.2 \%)$. None of these cases presented with bleeding manifestation.

Figure 1: Distribution of platelet count in cases of CRF

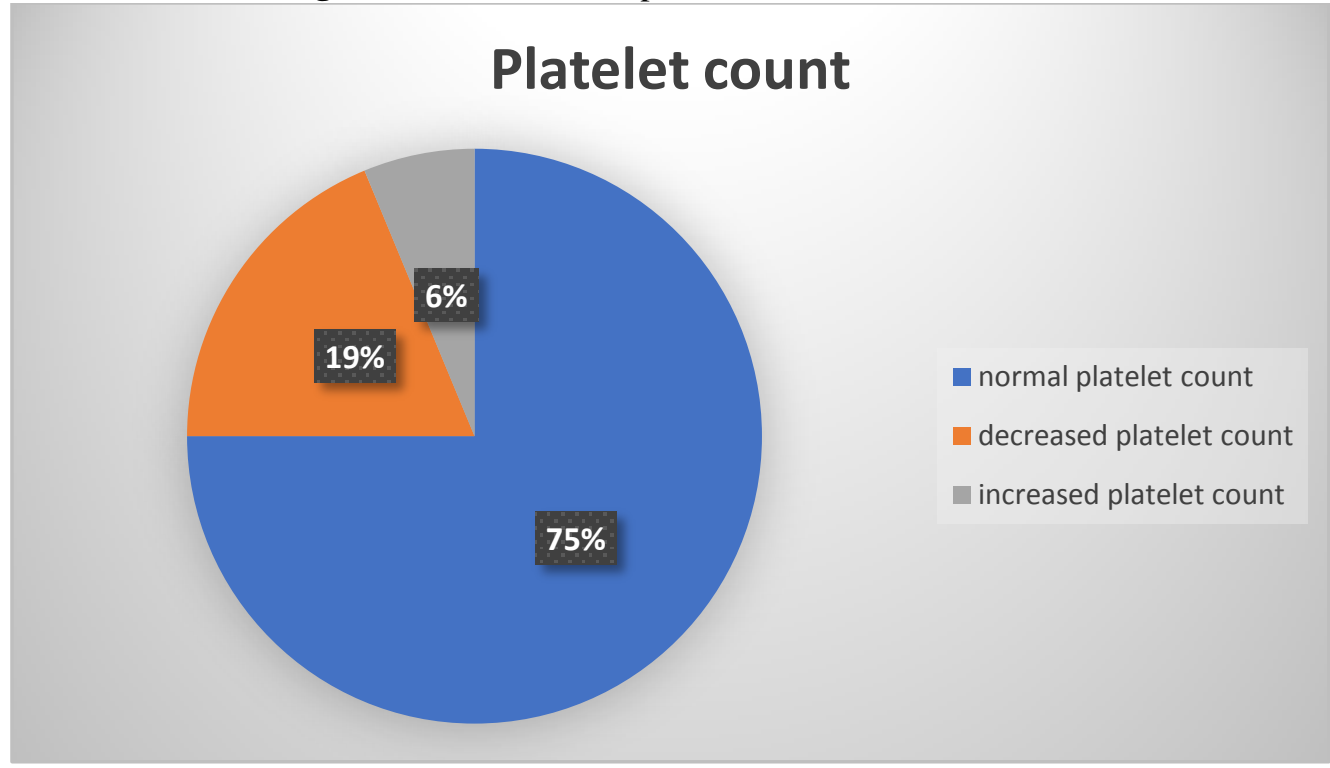

\section{Discussion}

The hematological parameters were analyzed in 32cases of chronic renal disease. All these cases revealed increased levels of blood urea and creatinine levels. Increased serum creatinine levels in cases of CRF are due to its reduced clearance. Serum creatinine levels are used as a diagnostic test to assess renal function and the levels more than $1.5 \mathrm{mg} / \mathrm{dl}$ indicate impairment of renal function ${ }^{6}$.

Majority of the cases were in the age group of 70-80years, with male pre-dominance. Type II diabetes mellitus, hypertension and obstructive uropathy account for the renal failure in most of the cases. Our study also revealed type II diabetes mellitus, obstructive uropathy and hypertension in $50 \%$ of cases as a contributing cause of renal failure. Anemia was seen in all the patients of chronic renal disease in the present study. Moderate anemia was the commonest feature. Normocytic normochromic RBC picture was seen in most cases. Total and differential WBC count is not significantly altered in cases of chronic renal failure. Though platelet count is not significantly altered, thrombocytopenia can be observed in few cases of chronic renal failure. Anemia is seen in all patients with $\mathrm{CRF}^{6}$. The association of anemia with renal failure was first noted by Richard Bright in $1936^{7}$. The severity of anemia increases with severity of disease ${ }^{8}$. There are three factors involved in the pathogenesis of anemia in cases which are deficiency of erythropoietin, shortened red cells survival and suppression of erythropoiesis.

In patients of chronic renal failure renal symptoms remain subtle in most of the cases and the presenting features are only symptoms of anemia ${ }^{4}$. Management of anemia in these cases improves the quality of life ${ }^{9}$.Chronic renal disease is associated with increased susceptibility to infections as seen in our study. Many studies have revealed that leucocyte chemotaxis is impaired in uremia. Platelet count varies in chronic renal disease. Also, altered platelet function with coagulation abnormalities are known ${ }^{10}$.Our study also revealed thrombocytopenia in $18.75 \%$ cases.

\section{Conclusion}

Patients with chronic renal failure show abnormal hematological parameters. The commonest of which is anemia. The anemia in CRF is normocytic normochromic and of moderate degree in most of the cases. Total and differential WBC count is not significantly altered in cases of CRF but few cases present with thrombocytopenia.However, a future study with larger sample size recommended. 


\section{References}

[1]. Gedela SR, VarmaPP, BaligaKV, Chawala ML, Rai R.Renal replacement therapy: its status in India, Medicine update 2004; 45156.

[2]. Levey AS,Coresh J. The NationalKidney Foundation: the K/DOQI clinical practice guidelines for chronic kidney diseases: evaluation, classification and stratification. Am J Kidney Dis 2002; 39:66.

[3]. Sakhuja V, Sud K. End stage renal disease in India and Pakistan: the burden of the disease and management issues. Kidney Int Suppl 2003; 63 S83; 115-8.

[4]. Means RTjr, Greer JP, Foerster J, Rodgers MG, et al. Anemia of chronic renal insufficiency. In wintrobe's clinical hematology.12 ed. Philadelphia:lipincott-williams \& wilkins;2009.Vol 1.1225-9

[5]. Macdougall IC, Eckardt KU. Oxford textbook of clinical nephrology. $3^{\text {rd }}$ ed.2008. Vol 3.1806-27.

[6]. Victor W.Rodwell. Conversion of amino acids to specialized products.In: Robert K Murray. Harper's illustrated Biochemistry. Twenty sixth edition, McGraw hill: 2003: chapter 31: 267

[7]. Singh NP, Agarwal L, Singh T. Anemia, iron studies and erythropoietin in patients of chronic renal failure. JAPI 1999;47(3):284-9

[8]. Suresh M, Mallikarjuna reddy N, Sharan B Singh M, Hari Krishna Bandi, Shravya Keerthi G, Chandrashekhar M. Hematological changes in Chronic Renal Failure. International Journal of Scientific and Research Publication 2012; 2(9):1-4.

[9]. Khanam S, Begum N, Begum S, Hoque EAM. Changes in hematological indices in different stages of chronic renal failure. J Bangla soc Physiol 2007 Dec;2:38-41

[10]. Schieppati A, Falanga A, Remui G. hematological abnormalities in chronickidney disease. In clinical hematological. 1st ed. New York. 2006. 1060-72. 